\title{
The Influence of Physical Training on Blood Levels of Human Growth Hormone, Testosterone and Procollagen in Young Rowers
}

\author{
Kaloupsis Socratis \\ Department of Aquatic Sports, University of Athens, PO box 17237, Dafni, Athens, Greece \\ E-mail: skaloups@phed.uoa.gr \\ Ditsios Kostas \\ A Orthopaedics Department, Aristotle University of Thessaloniki, PO box 54124, Thessaloniki, Greece \\ E-mail: ditsiosk@otenet.gr \\ Dessypris Athanasios \\ Department of Biochemistry and Molecular Biology, University of Athens, PO Box 17237, Dafni, Athens, Greece \\ Dimakopoulou Eleni (Corresponding author) \\ Department of Aquatic Sports, University of Athens, PO box 17237, Dafni, Greece \\ E-mail: edimakop@phed.uoa.gr \\ Kapoutsis Dimitrios \\ A Orthopaedics Department, Aristotle University of Thessaloniki, PO box 54124, Thessaloniki, Greece
}

Received: 15-06- 2016

doi:10.7575/aiac.ijkss.v.4n.3p.63
Accepted: 20-07- 2016

Published: 31-07- 2016

\begin{abstract}
Objective: The purpose of this study was to investigate muscle strength and skeletal age in trained and untrained pubertal boys and its relationship to the levels of Testosterone (T), Growth Hormone (GH) and Procollagen (PICP). Methods: Both the exercise and control groups consisted of 24 (mean 12.91, sd = 0.63) and $17($ mean $12.91, \mathrm{sd}=0.48)$ year old boys, respectively. The exercise group (EG), in addition to school activities, participated in a rowing training program for six months (rowing technique, strength \& aerobic exercises, $60 \mathrm{~min} /$ day, three days/week). The control group (CG) only participated in the school physical education program, two to three times/week. Hormonal concentrations were measured by radioimmunoassay techniques. Venus blood samples were taken at rest from both groups. Results: Testosterone was increased in both groups $(\mathrm{p}<0.001)$. Significant differences were found within groups in $\mathrm{T}$ before training $(\mathrm{p}<0.01)$ There was an increase of PICP in EG after training $(\mathrm{p}<0.01)$. Differences on GH were observed before the training period in both groups $(\mathrm{p}<0.01)$. Both groups significantly differed in upper and lower limbs strengths. Significant correlation was found between PICP and skeletal age in both $(p<0.05$ and $p<0.02$, respectively) Conclusions: The gains in muscle strength in both groups may partly be explained by the increase in the concentrations of hormone levels and the changes in body size.
\end{abstract}

Key words: skeletal age, muscle strength, anabolic hormones, rowing

\section{Introduction}

Participation in sport attracts many young people for a variety of reasons. Rowing is a demanding physical and mental workout. Along with rowing skills, young people can develop teamwork, unselfishness and initiative. It is well known in the world of sport sciences that the potential of physical training is related to hormones (Mero et al., 1990, Eliakim and Nemet, 2013, Nemet et al., 2012, Ramson et al., 2012). In addition, hormonal changes are also related to behavioral changes (Mansoubi et al., 2013). Hormones are biochemical indexes which help us diagnose an unsafe situation for the athlete, for instance overtraining and prevent it (Kuipers \& Keizer, 1988, Lehmann et al., 1993). Hormones are also related to the changes of body constitution, distribution of fat tissue and muscular strength (Rogol, 1994). There have been long term studies of the physiology of the athletes' endocrine system (Galbo, 1983, Hakkinen et al., 1989). Growth Hormone and $\mathrm{T}$ are both anabolic hormones, with $\mathrm{T}$ contributing to growth and function of reproductive tissues and to the increase of muscle and bone mass, and GH, being essential for the growth and the development of bones, liver and other organs. PICP is the most abundant type of collagen in most soft tissues and accounts for $>90 \%$ of the organic matrix of bone. In rowing, there have been studies investigating hormone concentrations referring to hormonal levels before and after a training program and a competitive effort, or throughout the different phases of a training season 
(Purge et al., 2006, Maestu et al., 2005). Vervoorn et al., (1991) found that prolonged heavy endurance training causes an increase and a decrease in the fasting levels of Cortisol and T, respectively. In another study improvement of performance was associated with increased GH and Cortisol (Snegovskaya \& Viru, 1993). Few studies have investigated the effect of PICP and its relation to skeletal age.

Therefore, the purpose of the present study was at to investigate the concentration levels of T, GH and PICP in young adolescent athletes participating in a six months rowing training program b) to examine the relation of these hormones to both strength and skeletal age.

\section{Methods}

\section{1 Participants}

Forty-one healthy male high school students, attending a school with special emphasis on physical education and sports (athletic high-school) volunteered to participate in this study. They were randomly assigned into 2 groups: an EG and a CG. A lottery system was used to randomly assign participants into these groups. All students and their parents received full information about the procedure of the study and gave their written consent. The study was approved by the Department of Physical Education of the University of Athens.

\subsubsection{Exercise Group (EG)}

This group consisted of 24 students (age: $12.8 \pm 0.63 \mathrm{yrs}$, height: $166.67 \pm 8.22 \mathrm{~cm}$, body mass: $58.42 \pm 9.37 \mathrm{~kg}$ ) who followed a six-month rowing training program, appropriately designed for this age group. They trained at least 3 times a week, enabling them to learn the basic rowing technique. The exercise program was designed for both upper and lower extremities. Duration of the training session was approximately 60 minutes. Each session was supervised by a coach. The training regimen of rowers was similar for each week of the study and consisted of $25 \%$ strength training, $60 \%$ endurance training and $15 \%$ technique training in single sculls, pair and in Concept II rowing ergometer (Morrisvile, USA).

\subsubsection{Control Group (CG)}

The CG consisted of 17 adolescent males (age: $12.91 \pm 0.47 \mathrm{yrs}$, height: $156.77 \pm 6.9 \mathrm{~cm}$, body mass: $47.89 \pm 8.38 \mathrm{~kg}$ ), who participated regularly in physical exercise classes at school and other leisure-time sports activities, without following a special training program.

\subsection{Procedure}

\subsubsection{Anthropometry}

Students' bare-foot standing height was measured with a special height measuring apparatus (Sega se v 91) to the nearest $0.1 \mathrm{~cm}$ and weight was determined using a scale (Sega 770) with a precision of $0.1 \mathrm{~kg}$. All anthropometric data were gathered by a single experienced investigator. Body Mass Index (BMI) was determined as the second power of body weight in kilograms divided by height in meters. Each student underwent a left hand and wrist X-ray in order to evaluate the skeletal age, according to the well known method of Greulich and Pyle (1959). The evaluation was conducted by an experienced doctor.

\subsubsection{Muscle Strength Measuring}

Students were tested after breakfast between 8 and 9 o'clock. On testing day, after a period of warm up, subjects were verbally encouraged to produce a maximal force at an angle of $90^{\circ}$ degree. Subjects were asked to sit on a Concept II rowing ergometer (Morrisvile, USA). A belt was adjusted around their back and a chain was connected with a strain gauge sensor (Dynamometer, ADW 15, Mantraweigh, UK 2000). All data was recorded in a portable pc. The knee joint was positioned at $90^{\circ}$ degree of flexion. Subjects then performed one maximum voluntary isometric contraction. The same procedure was followed for upper limb strength (biceps) as subjects lay prone in a gymnastic bench. The elbow joint was positioned at $90^{\circ}$ flexion. Subjects performed one maximum voluntary isometric contraction.

\subsubsection{Blood Tests}

After one day of rest from muscle strength measurement and 12 hours of fasting, T, GH and PICP levels were determined by Ria (Orion Diagnostica, Espoo, Finland). All hormones were analyzed on radioimmunoassay in the biochemical lab of the university.. Approximately $10 \mathrm{~mL}$ of blood was drawn from the antecubital vein using a gauge needle Vacutainer setup. Blood samples were centrifuged two times, each time for ten minutes (speed: 1500/ minute) in order to separate the red blood cells and serum. Serum was distributed into three different vacutainers which were frozen to $-20{ }^{\circ} \mathrm{C}$. In order to minimize the influence of diurnal fluctuation all samples were obtained between 8.30 and $11.00 \mathrm{am}$.

\subsection{Data Analyses}

Mean Values and Standard deviations were calculated for all variables. Differences between groups were determined using Repeated Measures Anova followed by Bonferroni post hoc comparisons. Paired Sample t- test was used to detect the differences before and after the study period. For every correlation analysis, Pearson's coefficient was calculated. The data in the tables are presented as mean \pm SD. Statistical significance was set at $p<0.05$. Data was analyzed using the IBM SPSS 19.0 (SPSS, Chicago, LII, USA). 


\section{Results}

General characteristics of both EG and CG are shown in Table 1. Significant differences were observed in both groups during the study period regarding skeletal age $(\mathrm{p}=0.001)$, height $(\mathrm{p}=0.001)$ and body weight $(\mathrm{p}=0.001)$. BMI changed significantly in the EG $(\mathrm{p}=0.01)$, but not in the CG $(\mathrm{p}=0.088)$. Both groups exhibited significant differences before the six-month training period in: skeletal age $(\mathrm{p}=0.021)$, in height $(\mathrm{p}=0.001)$ and in body weight $(\mathrm{p}=0.001)$. After the study period, significant differences were also observed (skeletal age $(p=0.002)$, height $(p=0.001)$, body weight $(p=0.001)$ and BMI ( $\mathrm{p}=0.039))$. Chronological age and skeletal age differed before $(\mathrm{p}=0.001)$ and after $(\mathrm{p}=0.000)$ the study period in EG. In addition, in the CG the chronological age and skeletal age were not different before $(\mathrm{p}=0.964)$ but were after $(\mathrm{p}=$ 0.009).

Table 1. General characteristics of EG and CG (Mean $\pm S D)$

\begin{tabular}{l|cccc}
\hline \multicolumn{1}{c|}{ Variables } & \multicolumn{2}{c}{$E G(n=24)$} & \multicolumn{2}{c}{ CG $(\boldsymbol{n}=17)$} \\
& Pre & Post & Pre & Post \\
& $12.8 \pm 0.63$ & $13.4 \pm 0.63$ & $12.9 \pm 0.5$ & $13.5 \pm 0.5$ \\
Chron. age(yrs) & $13.5 \pm 0.91$ & $14.2 \pm 1.06$ & $12.9 \pm 0.7$ & $13.3 \pm 0.7$ \\
Skeletal Age & $166.6 \pm 8.22$ & $170.3 \pm 7.94$ & $156.7 \pm 6.9$ & $160.9 \pm 6.5$ \\
Height $(\mathrm{cm})$ & $58.4 \pm 9.37$ & $62.1 \pm 8.39$ & $47.8 \pm 8.4$ & $51.5 \pm 7.8$ \\
Weight $(\mathrm{Kg})$ & $20.6 \pm 2.36$ & $21.3 \pm 2.02$ & $19.4 \pm 2.7$ & $19.8 \pm 2.6$ \\
BMI $\left(\mathrm{Kg} / \mathrm{m}^{2}\right)$ & & & &
\end{tabular}

T mean concentrations and significant difference, of the EG and CG, before and after the training period, are shown in figure 1 .

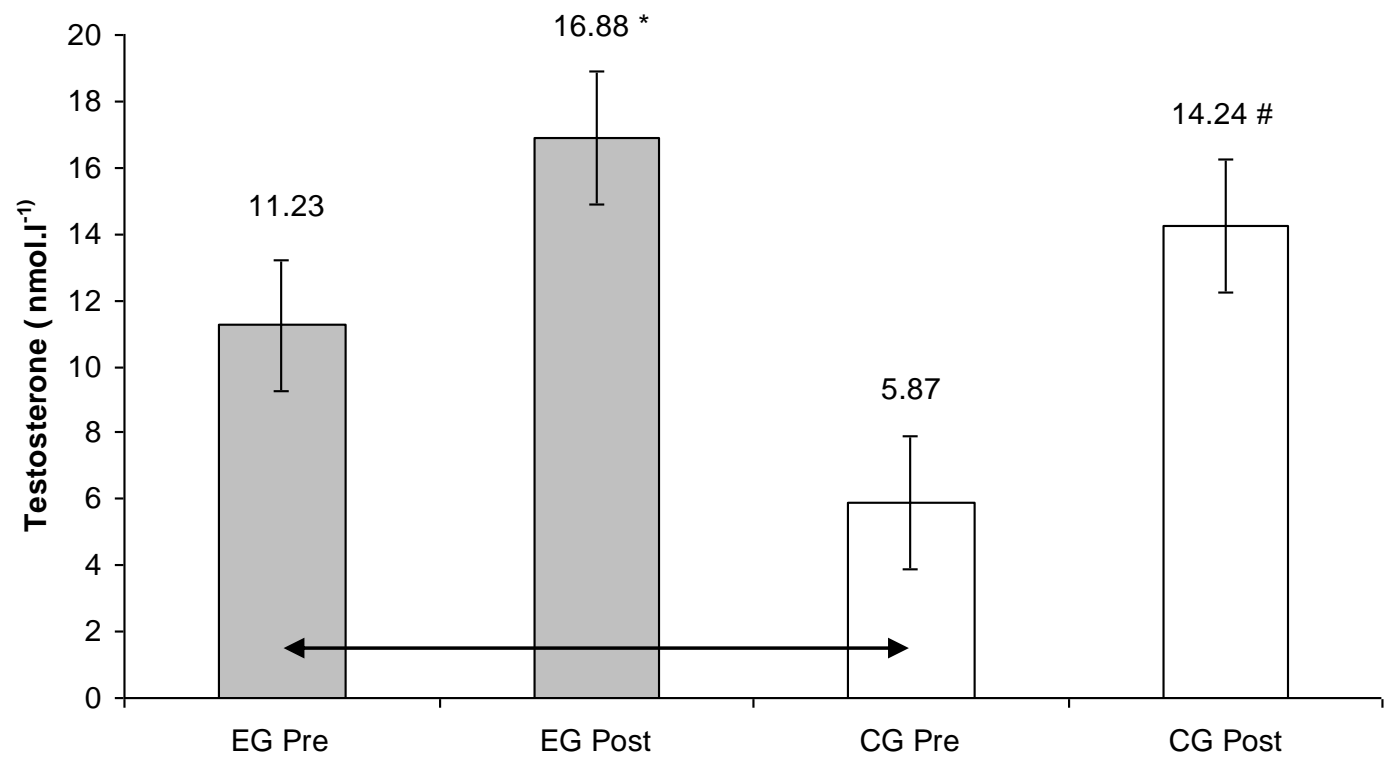

Figure1. Concentrations and differences of $\mathrm{T}$ in $\mathrm{EG}$ and CG before and after the training period (Mean $\pm \mathrm{Sd})$. significant difference $\mathrm{p}<0.05, *$ EG pre-post, \# CG pre-post, 
Figure 2 presents GH mean concentrations and significant difference, of the EG and CG, before and after the study period.

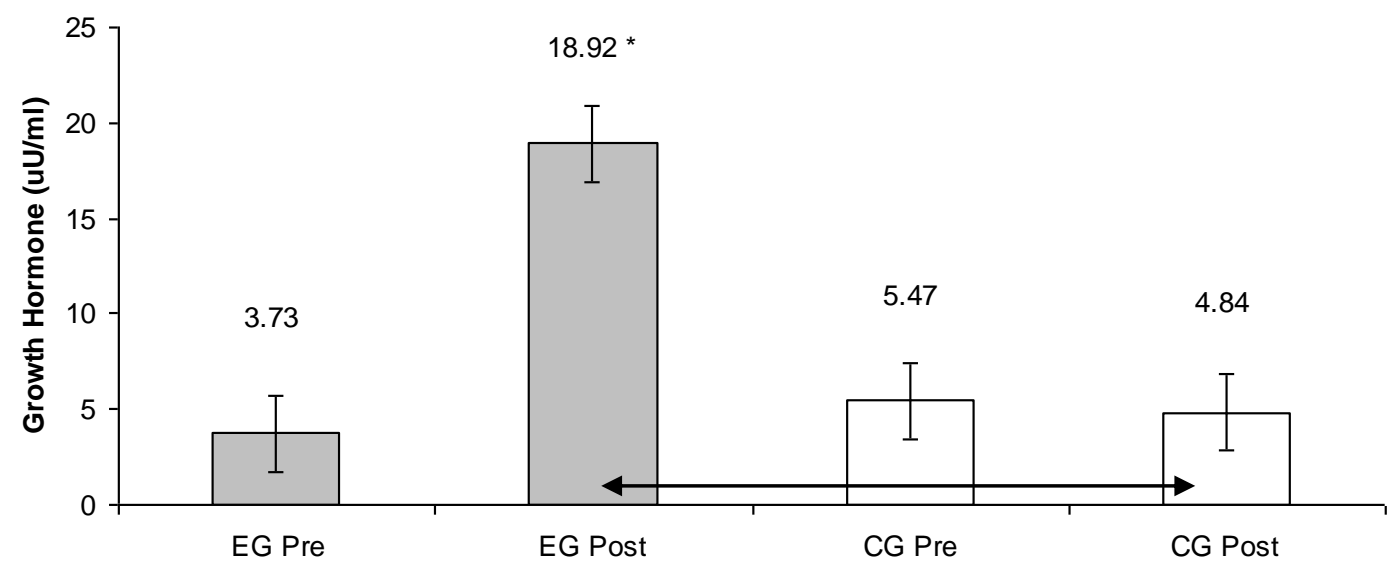

Figure 2. Concentrations and differences of GH in EG and CG before and after the training period (Mean \pm Sd).significant difference $\mathrm{p}<0.05, *$ EG pre-post

In figure 3 PICP mean concentration before and after the training period for both groups is shown (and significant differences). EG and CG had significant differences in T concentrations ( $p=0.013)$ in the beginning of the study. After the training period, they had significant differences in $\mathrm{GH}(\mathrm{p}=0.001)$. Table 2 summarizes the upper and lower limbs strength of the EG and the CG in the start and in the end of the six-month training period. The two groups had significant differences in upper limbs strength $(\mathrm{p}=0.001)$ and in lower limbs strength $(\mathrm{p}=0.001)$ in the start of the study and at the end of the training period also differed in upper $(\mathrm{p}=0.001)$ and lower $(\mathrm{p}=0.001)$ limb strength.

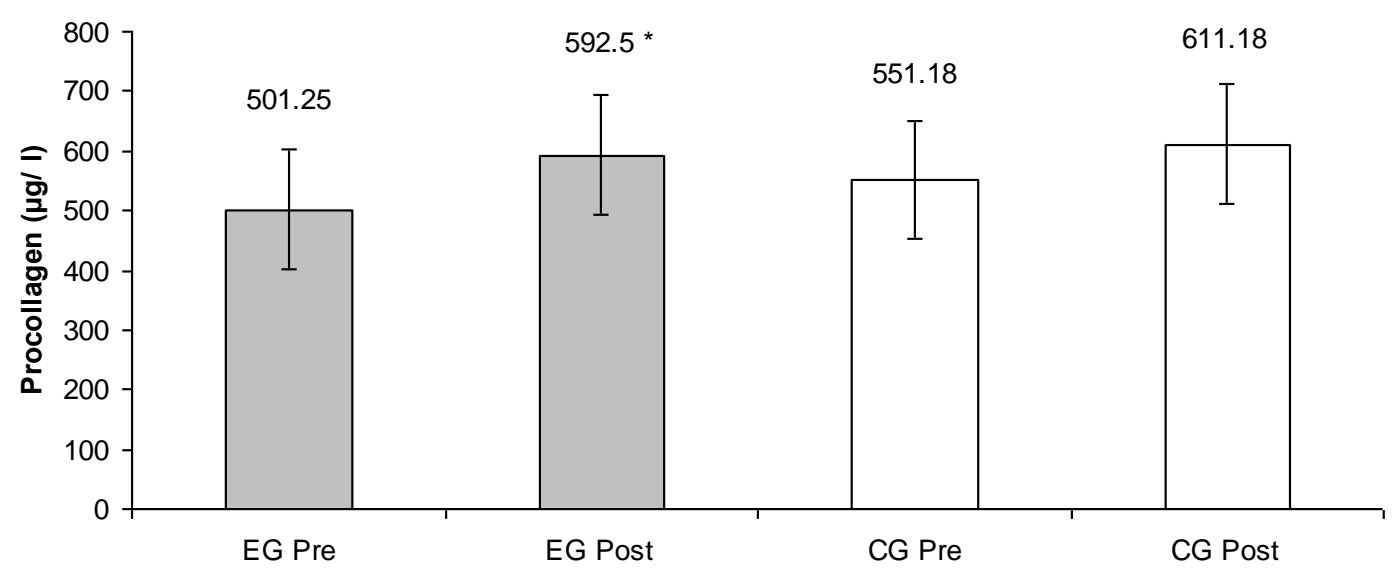

Figure 3. Concentration of PICP and differences in each group before and after the training program (Mean $\pm \mathrm{Sd})$. significant difference $\mathrm{p}<0.05$, EG pre-post

Table 2. Differences of Upper and Lower limbs' strength of EG and CG before and after a six-month training period (Mean $\pm S D)$.

\begin{tabular}{l|cccc}
\hline \multicolumn{1}{c|}{ Variables/Groups } & Pre training & Post training & $\boldsymbol{t}$ & p \\
\hline Upper Limb Strength / EG & $41.83 \pm 10.34^{*}$ & $50.39 \pm 10.61 \#$ & 9.71 & 0.001 \\
Lower Limb Strength / EG & $87.08 \pm 16.29$ & $106.87 \pm 18.69$ & 7.48 & 0.001 \\
Upper Limb Strength / CG & $29.38 \pm 5.17$ & $31.94 \pm 6.55$ & 4.86 & 0.001 \\
Lower Limb Strength / CG & $60.73 \pm 10.48$ & $64.85 \pm 11.74$ & 9.67 & 0.001 \\
\hline
\end{tabular}

* p <0.05 EG-CG (upper, lower limb strength pre), \# p<0.05 EG-CG (upper, lower limb strength post)

Significant correlation was observed between $\mathrm{T}$ and upper limbs strength (before $0.009, \mathrm{r}=0.5$, after $\mathrm{p}<0.010, \mathrm{r}=0.7$ ) and $\mathrm{T}$ and lower limbs strength (before $\mathrm{p}<0.039$, after $\mathrm{p}<0.004, \mathrm{r}=0.7$ ) in the EG. This correlation was significant before and after the study period. In the CG, significant correlations were found between GH and upper limbs strength 
$(\mathrm{p}<0.043, \mathrm{r}=0.5)$ before training and after $(\mathrm{p}<0.009, \mathrm{r}=0.6)$. Significant correlation between $\mathrm{GH}$ and lower limb strength was found only after the training program $(\mathrm{p}<0.008, \mathrm{r}=0.6)$ in CG. No significant correlation was found between PICP and strength in both groups. In the EG significant correlation was found between PICP and skeletal age, after training $(\mathrm{p}<0.004, \mathrm{r}=0.5)$. Significant correlation was observed before and after training between PICP and skeletal age in CG. The correlations were 0.05 and 0.016 , respectively. No significant correlations were found between chronological age and hormones concentrations neither in EG nor in CG.

\section{Discussion}

Primary findings demonstrated that both groups had a significant increase in skeletal age, height and body weight. BMI significantly increased only in EG. The EG anthropometric characteristics compared to a reference group of untrained Greek children by means of percentiles (P) (Kaloupsis et al., 2008) presented high percentile values for height (P83), weight (P70) and BMI (P52). Significant differences between the two groups was noticed as far as skeletal age, height, body weight and BMI were concerned. The EG had advanced skeletal age. Bouchard and Malina (1977) found that athletes of various sports had advanced skeletal compared to chronological age. Similar results are reported by Hale (1956) and Szabo et al. (1972). Malina et al. (1982) found that children participating in basketball, football, rowing and swimming had advanced skeletal age compared to sedentary children of the same chronological age. Advanced skeletal age is also reported for Polish and Czech boys regularly involved in sports (Parizkova, 1974). The increase in height for both groups was expected as a result of somatic growth and maturation (Kobayashi et al.,1978, Prader, 1983, Rogol et al., 2000). Similarly, body weight was significantly different. Study group was heavier. According to Malina and Bouchard (1991) children with advanced biological maturity tend to present increased body weight.

A significant increase in $\mathrm{T}$ levels was observed in both groups. Before training, $\mathrm{T}$ levels differed significantly $(\mathrm{p}=0.013)$ between the two groups. After training period, there were no significant differences $(\mathrm{p}=0.324)$. The results of Mero et al. (1990) suggested that $\mathrm{T}$ concentration increased in boy athletes during a 1- year training period. Cacciari et al. (1990) who studied football players found the same results as Mero et al. (1990). Ramos et al. (1998) found increased T levels in older boys and a specific gain in muscle strength. Frasier et al. (1969) studied boys during childhood and adolescence and found $\mathrm{T}$ levels rising significantly after the age of 11. Similar findings are reported in Wieland et al. (1971). Another study, demonstrated that 2 months of strength training resulted in significant increase in the level of T (Tsolakis et al., 2007). In the present study, the GH concentrations increased after the study period in EG. Steinacker et al. (2000) found a 10\% increase in human GH during a high load training phase. The two groups differed significantly only after the training period in GH. No correlation was found between GH and chronological age (Greenwood et al., 1964). According to Hartley (1975) and Bunt et al. (1986), GH levels increase during training period. Tsolakis et al. (2003) found significant differences in T and GH among athletes group (handball, rowing, running, basketball, fencing etc.). The mean $\mathrm{T}$ of the control group (sedentary boys) did not differ from those of the corresponding exercise group. The study by Tsolakis et al. (2003) demonstrated the importance of the specificity of the training stimulus in the hormonal adaptations of pre-pubertal sedentary subjects.

In another study (Kaloupsis, 1996), 61 subjects were studied. They were arranged randomly in 4 groups (2 exercise and 2 control groups). The study groups consisted of subjects of different chronological ages (13-14yrs) and rowing experience (novice and more experienced). For each exercise group there was a corresponding group of the same age who did not exercise systematically. The subjects of the study group underwent a 6-month rowing training program. The results of this study showed a post exercise increase in $\mathrm{T}$ concentration in all groups which is in line with the findings of our results. PICP was increased only in EG and was found to be correlated with skeletal age in both groups. This result was expected, as PICP is the most abundant type of collagen in most soft tissues and accounts for $>90 \%$ of the organic matrix of bones. Assessment of the turnover rhythm of this collagen is particularly relevant to bone metabolism. The assay of the carboxyterminal propeptide of type I procollagen provides a method of estimating the rate of type I collagen synthesis in the body (Melkko et al., 1990). Another study by Fujimura et al. (1997) in males (23$31 \mathrm{yrs}$ ) reports slight increase of PICP in the training group (4 months, weight training) after the first month of resistance training. The PICP returned to baseline thereafter. In the sedentary group the PICP significantly decreased. These results are in line with our study.

A significant increase of muscle strength of upper (biceps) and lower limbs was observed in both groups. In EG (quadriceps, biceps femoris, gastrocnemious), $\mathrm{T}$ was positively correlated to muscle strength of upper and lower extremities. Testosterone has been shown to stimulate anabolic processes in skeletal muscles and appears to be the principal hormone responsible for the development of strength (Hakkinen and Parakin, 1993). Our results are in agreement with another study (Ramos et al., 1998) which found a positive correlation between T levels and absolute muscle strength in boys (11-12yrs). Increase in strength can be due to several factors including changes in body size and composition. Gregory et al. (1992) found that height, weight, and muscle mass increase with age and are correlated with gains in muscle strength. Age and weight is suggested to be the most important factors (Falker, 1978). The increase in muscle strength can be explained also by the context of the specific training (rowing technique), endurance and resistance training. The rowers (EG) probably recruited both fast and slow twitch muscle fibres in their training, which induced effects in both cell types. Synchronous strength training and increased $T$ levels may affect muscle growth (Richter, 1986).

In this study, training can be a stimulus for increased hormone levels. The increase is observed in puberty (13yrs) and in the EG hormone levels increased more. Our results are in agreement with the study of Zakas et al. (1994) who 
suggested that training elevates serum $\mathrm{T}$ and $\mathrm{GH}$ concentrations in puberty (13yrs), when there is a stimulus such as a high intensity and duration in exercise. In summary, significant increases in muscle strength occurred in both groups. The gains in muscle strength may partly be explained by the increase in the concentrations of hormonal levels and the changes in body size.

\section{Conclusion}

Puberty is a dynamic period of development in body size, shape and composition. Our study concludes that either mild or high training can change the levels of T, GH and PICP in puberty. The significant increase in hormonal levels of T, GH and PICP concentrations during the six-month training program are of great importance as this information might be useful to coaches for designing training programs for these age groups.

\section{References}

Bouchard C. and Malina R.M. (1977). Skeletal maturity in a Pan American Canadian Team. Canadian Journal of Applied Sport Science, 2, 109-114.

Bunt J.C., Boileau R.A., Bahr J.M., Nelson R.A. (1986). Sex and training differences in human growth hormone levels during prolonged exercise. Journal of Applied Physiology, 61(5), 1796-801.

Cacciari E., Mazzanti L., Tassinari D., Bergamaschi R., Magnani C., Zappula F., Nanni G., Codianchi C., Ghini T., Pini R., Tani G. (1990). Effects of sport (football) on growth : auxological, anthropometric and hormonal aspects. European Journal of Applied Physiology and Occupational Physiology, 61(1-2), 149-158.

Eliakim A., Nemet D. (2013). The endocrine response to exercise and training in young athletes. Pediatric Exercise Science, 25, 605-615.

Falker J. (1978). Plantar flexor strength testing using the Cybex isokinetic dynamometer. Physical Therapy, 58, 847-50.

Frasier S.D., Gafford F., Horton R. (1969). Plasma androgens in childhood and adolescence. Journal of Clinical Endocrinology and Metabolism, 29, 1404-8.

Fuzimura R., Ashizawa N., Watanabe M., Mukai N., Amagai H., Fukubayashi T., Hayashi K., Tokuyama K., Suzuki M. (1997). Effect of resistance exercise training on bone formation and resorption in young male subjects assessed by biomarkers of bone metabolish. Journal of Bone and Mineral Research, 12(4), 656-662.

Galbo H. (1983). Hormonal and metabolic adaptations to exercise. Stuttugart: Thieme, p. 2-27.

Greenwood F.C., Hunter W.M., Marrian V.J. (1964). Growth hormone levels in children and adolescents. British Medical Journal, 1, 25-6.

Gregory J.W., Greene S.A., Thompson J., Scrimgeour C.M., Rennie M.J. (1992). Effects of oral testosterone undecanoate on growth, body composition, strength and energy expenditure of adolescents boys. Clinical Endocrinology, 37, 207-13.

Greulich W.W., Pyle S.I. (1959). Radiographic atlas of skeletal development of the hand and wrist. Stanford University Press.

Hakkinen K., Keskinen K.L., Alen M., Komi P.V., Kauhanen H. (1989). Serum hormone concentrations during prolonged training in elite endurance trained and strength trained athletes. European Journal of Applied Physiology and Occupational Physiology, 59, 233-238.

Hakkinen K., Pakarinen A. (1993). Muscle strength and serum testosterone, cortisol and SHBG concentrations in middle-aged and elderly men and women. Acta Physiologica Scandinavica, 148, 199-207.

Hale J. (1956). Physiological maturity of Little League Baseball players. Research Quarterly, 27, 276-284.

Hartley L. (1975). Growth hormone and catecholamine response to exercise in relation to physical training. Medicine and Science in Sports, 7(1), 34-36.

Kaloupsis S. (1996). The effect of rowing training of male rowers of adolescence age on the levels of selective anthropometrics ergometric and hormonal parameters with the rate of biological maturation. Phd Thesis.

Kaloupsis S., Bogdanis G.C., Dimakopoulou E., Maridaki M. (2008). Anthropometric characteristics and somatotype of young Greek rowers. Biology of Sport, 25(1), 57-68.

Kobayashi K., Kitamura K., Miura M., Sodeyama H., Murasa Y., Miyashita M., Matsui H. (1978). Aerobic power as related to body growth and training in Japanese boys. A longitudinal study. Journal of Applied Physiology, 44, 666-672.

Kuipers H., Keizer A. (1988). Overtraining in elite athletes. Sports Medicine, 6, 79-92.

Lehmann M., Forster C., Keul J. (1993). Overtraining in endurance athletes: a brief review. Medicine and Science in Sports and Exercise, 25, 854-61.

Maestu J., Jurimae J., Jurimae T. (2005). Hormonal response to maximal rowing before and after heavy increase in training volume in highly trained male rowers. Journal of Sports Medicine \& Physical Fitness, 45(1), 121-6. 
Malina R., Meeleski B., Shoup R. (1982). Anthropometric, body composition and Maturity characteristics of selected school age athletes. Pediatric Clinics of North America, 29 (6), 1305-23.

Malina R.M., Bouchard C. (1991). Physical activity as a factor in growth, maturation and performance. Growth, maturation, and physical activity. Human Kinetics, Champaign I 11, p. 371-390.

Mansoubi M., Hojjat S., Shojaei M. (2013). Effect of national preparation training on salivary testosterone, cortisol, and some psychological factors on Iranian female rowers. European Journal of Experimental Biology, 3(2), 13-17.

Melkko J., Niemi S., Risteli L., Risteli J. (1990). Rarioimmunoassay of the Carboxyterminal propeptide of Human Type I Procollagen. Clinical Chemistry, 36(6):1328-1332.

Mero A., Jaakkola L., Komi P.V. (1990). Serum hormones and physical performance capacity in young boy athletes during a 1-year training period. European Journal of Applied Physiology, 60: 32-37.

Nemet D., Portal S., Zadik Z., Pliz-Burstein R., Adler-Portal D., Meckel Y., Eliakim A. (2012). Training increases anabolic response and reduces inflammatory response to a single practice in elite male adolescent volleyball players. Journal of Pediatric Endocrinology and Metabolism, 25 (9-10), 875-880.

Parizkova J. (1974). Particularities of lean body mass and fat development in growing boys as related to their motor activity. Acta Pediatrica belgica, 28(Suppl): 233-243.

Prader A. (1983). Biomedical and endocrinological aspect of normal growth and development. Biomedical Aspects of Normal Growth, 1-21.

Purge P., Jurimae J., Jurimae T. (2006). Hormonal and psychological adaptation in elite male rowers during prolonged training. Journal of Sports Science, 24(10), 1075-1082.

Ramos E., Frontera W.R., Liopart A., Feliciano D. (1998). Muscle strength and Hormonal Levels in Adolescents: Gender Related Differences. International Journal of Sports Medicine, 19: 526-531.

Ramson R., Jurimae J., Jurimae T., Maestu J. (2012). The effect of 4-week training period on plasma neyropeptide Y, leptin and ghrelin response in male rowers. European Journal of applied Physiology, 112(5), 1873-1880.

Richter E.A. (1986). Hormones, exercise and skeletal muscle. Scandinavian Journal of Sports Science, 8, 35-41.

Rogol A.D. (1994). Growth at puberty: interaction of androgens and growth hormone. Medicine and Science in Sports and Exercise, 26, 767-70.

Rogol A.D., Clark P.A., Roemmich J.N. (2000). Growth and pubertal development in children and adolescents: effects of diet and physical activity. American Journal of Clinical Nutrition, 72 (suppl), 521S-8S.

Snegovskaya V., Viru A. (1993). Elevation of cortisol and growth hormone levels in the course of further improvement of performance capacity in trained rowers. International Journal of Sports Medicine, 14, 202-207.

Steinacker J.M., Lormes W., Kellmann M., et al. (2000). Training of junior rowers before world championships: effects on performance, mood state and selected hormonal and matabolic responses. Journal of Sports Medicine and Physical Fitness, 40, 327-35.

Szabo S., Doka J., Apor P., Somogyvar K. (1972). Die Beziehugh zwischen Knochenlebensalter funktionel anthropometrischen Daten und der aeroben kapazitat. Schweizerische Zeitschhrift Sportmedizin, 20, 109-115.

Tsolakis C., Bogdanis G.C. (2007). Influence of resistance training on anabolic hormones in prepubertal and pubertal males. Journal of Exercise Science and Physiology, 3(1), 1-11.

Tsolakis C., Messinis D., Stergioulas A., Dessypris A. (2000). Hormonal responses after training and detraining in prepubertal and pubertal boys. Journal of Strength and Conditional Research, 14(4), 399-404.

Tsolakis C., Xekouki P., Kaloupsis S., Karas D., Messinis D., Vagenas G., Dessypris A. (2003). The influence of exercise on growth hormone and testosterone in prepubertal and early-pubertal boys. Hormones, 2(2), 103-112.

Vernoorn C., Quist A.M., Vermulst L.J., et al. (1991). The bahavior of the plasma free testosterone/cortisol ratio during a season of elite rowing training. International Journal of Sports Medicine, 12(3), 257-63.

Wieland R.G., Chen J.C., Zorn E.M., Hallberg M.C. (1971). Correlation of growth pubertal staging, growth hormone, gonadotropins, and testosterone levels during pubertal growth spurt in males. Journal of Pediatrics. 79, 999-1002.

Zakas A., Mandroukas K., Karamouzis M., Panagiotopoulou G. (1994). Physical training, growth hormone and testosterone levels and blood pressure in prepubertal, pubertal and adolescent boys. Scandinavian Journal of Medicine and Science in Sports, 4, 113-118. 